\title{
Cost-effectiveness of lumbar discectomy and single-level fusion for spondylolisthesis: experience with the NeuroPoint-SD registry
}

\author{
Praveen V. Mummaneni, M.D., ${ }^{1}$ Robert G. Whitmore, M.D., ${ }^{2,3}$ Jill N. Curran, M.S., ${ }^{2,3}$ \\ John E. Ziewacz, M.D., M.P.H., ${ }^{1,6}$ Rishi Wadhwa, M.D., ${ }^{1}$ Christopher I. Shaffrey, M.D., 5 \\ Anthony L. Asher, M.D., ${ }^{6}$ Robert F. Heary, M.D., 7 Joseph S. Cheng, M.D., ${ }^{8}$ \\ R. John Hurlbert, M.D., Ph.D., ${ }^{9}$ Andrea F. Douglas, M.D., ${ }^{3}$ Justin S. Smith, M.D., Ph.D., 5 \\ Neil R. Malhotra, M.D., ${ }^{4}$ Stephen J. Dante, M.D., ${ }^{4}$ Subu N. Magge, M.D.,${ }^{2}$ Michael G. Kaiser, M.D., ${ }^{10}$ \\ Khalid M. Abbed, M.D., ${ }^{11}$ Daniel K. Resnick, M.D., ${ }^{12}$ and Zoher Ghogawala, M.D. ${ }^{2,3}$
}

${ }^{1}$ Department of Neurological Surgery, University of California, San Francisco, California; ${ }^{2}$ Alan and Jacqueline Stuart Spine Research Center, Department of Neurosurgery, Lahey Hospital and Medical Center, Burlington, Massachusetts; ${ }^{3}$ Wallace Trials Center, Greenwich Hospital, Greenwich, Connecticut; ${ }^{4}$ Department of Neurosurgery, University of Pennsylvania, Philadelphia, Pennsylvania; ${ }^{5}$ Department of Neurosurgery, University of Virginia, Charlottesville, Virginia; ${ }^{6}$ Carolina Neurosurgery \& Spine, Charlotte, North Carolina; ${ }^{7}$ Rutgers New Jersey Medical School, Newark, New Jersey; ${ }^{8}$ Department of Neurological Surgery, Vanderbilt University Medical Center, Nashville, Tennessee; ${ }^{9}$ Department of Clinical Neurosciences, University of Calgary Spine Program, Calgary, Alberta, Canada; ${ }^{10}$ Department of Neurosurgery, Columbia University, New York, New York; ${ }^{11}$ Department of Neurosurgery, Yale University School of Medicine, New Haven, Connecticut; and ${ }^{12}$ Department of Neurological Surgery, University of Wisconsin School of Medicine and Public Health, Madison, Wisconsin

Object. There is significant practice variation and uncertainty as to the value of surgical treatments for lumbar spine disorders. The authors' aim was to establish a multicenter registry to assess the efficacy and costs of common lumbar spinal procedures by using prospectively collected outcomes.

Methods. An observational prospective cohort study was completed at 13 academic and community sites. Patients undergoing single-level fusion for spondylolisthesis or single-level lumbar discectomy were included. The 36-Item Short Form Health Survey (SF-36) and Oswestry Disability Index (ODI) data were obtained preoperatively and at 1, 3, 6, and 12 months postoperatively. Power analysis estimated a sample size of 160 patients: lumbar disc (125 patients) and lumbar listhesis (35 patients). The quality-adjusted life year (QALY) data were calculated using 6-dimension utility index scores. Direct costs and complication costs were estimated using Medicare reimbursement values from 2011, and indirect costs were estimated using the human capital approach with the 2011 US national wage index. Total costs equaled $\$ 14,980$ for lumbar discectomy and $\$ 43,852$ for surgery for lumbar spondylolisthesis.

Results. There were 198 patients enrolled over 1 year. The mean age was 46 years $(49 \%$ female) for lumbar discectomy $(n=148)$ and 58.1 years $(60 \%$ female) for lumbar spondylolisthesis $(n=50)$. Ten patients with disc herniation $(6.8 \%)$ and 1 with listhesis $(2 \%)$ required repeat operation at 1 year. The overall 1-year follow-up rate was $88 \%$. At 30 days, both lumbar discectomy and single-level fusion procedures were associated with significant improvements in ODI, visual analog scale, and SF-36 scores $(\mathrm{p}=0.0002)$, which persisted at the 1 -year evaluation $(\mathrm{p}<0.0001)$. By 1 year, more than $80 \%$ of patients in each cohort who were working preoperatively had returned to work. Lumbar discectomy was associated with a gain of 0.225 QALYs over the 1-year study period (\$66,578/ QALY gained). Lumbar spinal fusion for Grade I listhesis was associated with a gain of 0.195 QALYs over the 1-year study period (\$224,420/QALY gained).

Conclusions. This national spine registry demonstrated successful collection of high-quality outcomes data for spinal procedures in actual practice. These data are useful for demonstrating return to work and cost-effectiveness following surgical treatment of single-level lumbar disc herniation or spondylolisthesis. One-year cost per QALY was obtained, and this cost per QALY is expected to improve further by 2 years. This work sets the stage for real-world analysis of the value of health interventions. (http://thejns.org/doi/abs/10.3171/2014.3.FOCUS1450)

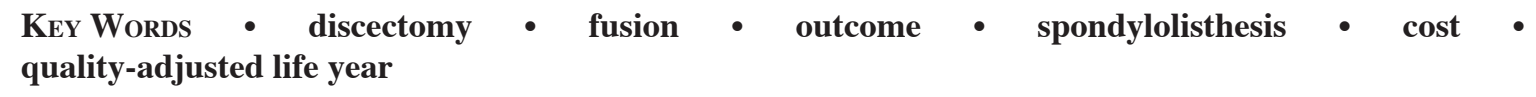

\footnotetext{
Abbreviations used in this paper: $\mathrm{CPT}=$ current procedural terminology; DRG = diagnosis-related group; HIPAA = Health Insurance Portability and Accountability Act; HRQOL = health-related quality of life; NeuroPoint-SD = NeuroPoint-Spinal Disorders; NPA = NeuroPoint Alliance; ODI = Oswestry Disability Index; QALY $=$ quality-adjusted life year; RCT $=$ randomized controlled trial; SF-6D = 6-dimension utility index; SF-12 and SF-36 = 12and 36-Item Short Form Health Survey; SPORT = Spine Patient Outcomes Research Trial.
}

$\mathrm{W}$ ITH implementation of the Patient Protection and Affordable Care Act set for 2014, there is increased interest in medical resource allocation and an emphasis on determining the value of health interventions. One of the primary areas of importance for researchers and policymakers is the cost burden of lumbar spine disorders for US society. ${ }^{18}$ The economic impact of lumbar spine disorders is now estimated to exceed 
$\$ 100$ billion per year ${ }^{8,9}$ and is nearly equal to the costs associated with treating all types of cancer. ${ }^{22}$ Although there is extensive literature on patient outcomes and costs following lumbar spinal surgery, there are very few Level 1 studies available to influence practice patterns. ${ }^{29,30}$ The Spine Patient Outcomes Research Trial (SPORT) data for lumbar disc herniation, spinal stenosis, and degenerative spondylolisthesis have in part suggested that the heterogeneity of lumbar spine disorders and patient preferences for treatment demonstrate that randomized controlled trial (RCT) methodology is difficult or impossible to apply to this population..$^{37,39,40}$

A prospective, nonrandomized registry has the advantage of being able to collect high-quality, prospective data with validated outcome tools that may more closely represent actual practice conditions than an RCT. Therefore, real clinical effectiveness data may be derived from registry studies. The aim of this registry study (NeuroPoint-Spinal Disorders [NeuroPoint-SD]) was to create an alliance of tertiary and community-based spine surgeons with a simple web-based infrastructure to collect outcomes data for common lumbar spinal procedures. NeuroPoint-SD demonstrated clinical effectiveness for 2 common lower back surgical procedures: lumbar discectomy and lumbar spinal fusion for spondylolisthesis. ${ }^{14}$ At 30 days, lumbar discectomy and single-level fusion procedures were associated with significant improvements in Oswestry Disability Index (ODI), visual analog scale, and 36-Item Short Form Health Survey $(\mathrm{SF}-36)$ scores $(\mathrm{p}=0.0002)$ that persisted over the 1 -year follow-up period $(\mathrm{p}<0.0001){ }^{14}$

The purpose of this analysis was to determine the cost-effectiveness from a societal perspective of lumbar discectomy and single-level lumbar fusion by using the prospective data collected from NeuroPoint-SD. The calculated cost per quality-adjusted life year (QALY) gained is placed into context by comparing it to the societal willingness-to-pay threshold as well as to other common operations such as total knee and hip replacement.

\section{Methods}

\section{Study Design}

A prospective, observational cohort registry study enrolled patients from 13 sites over a 1-year period and collected data from unselected patients undergoing lumbar discectomy or single-level fusion for spondylolisthesis. Outcomes were measured and observed over a 1-year period postoperatively.

\section{Data Coordination}

Institutional review board approval of the clinical protocol was obtained and research contracts were executed for this prospective registry at 13 academic and community sites nationwide in September 2010. Patient data were managed at the central coordinating center (Wallace Clinical Trials Center). All patient data were de-identified before transfer from each treating institution to protect patient confidentiality, in compliance with the Health Insurance Portability and Accountability Act (HIPAA). All patient data were entered into a secure, HIPAA-compliant, internet-based data management platform, the NeuroPoint
Alliance (NPA), which was developed by Outcome Sciences in conjunction with the American Association of Neurological Surgeons. Enrollment occurred over a 1-year period (September 2010-September 2011).

\section{Data Sources and Measurement}

All questionnaires were administered in the outpatient office setting unless the subject was not seen in the specifically required timeframe. In this situation, the subject was mailed the questionnaires to complete and return to the study site coordinator. Subjects completing the questionnaires at home were instructed to call study site coordinators with any questions. In addition, site coordinators reviewed questionnaires for completeness. Subjects were contacted via phone to assess work status, to document any complications during the study period, and to address and complete any missing data from the questionnaires. Each patient who failed to return followup questionnaires was contacted 3 times via mail and/or phone call to ensure maximal patient compliance.

\section{Study Population}

Patients 18-80 years of age who had either symptomatic lumbar disc herniation (Fig. 1) that was recalcitrant to noninvasive therapies for at least 6 weeks, or symptomatic lumbar degenerative spondylolisthesis (Fig. 2)with or without radiculopathy-that was recalcitrant to noninvasive therapies for at least 3 months were eligible. Patients were excluded for any of the following reasons: 1) history of previous lumbar spinal surgery at the level of disc herniation or spondylolisthesis; 2) significant motor weakness on manual muscle testing of $3 / 5$ or less (that is, foot drop) or cauda equina syndrome; 3) cancer, infection, or fracture involving any portion of the spine; and 4) pregnancy. Each site was permitted to enroll up to 25 unselected patients within the 1-year study period.

Patients were recruited from 13 sites without regard to sex, race, age, language preference, or socioeconomic status. There was no specific advertising to recruit patients, although the clinical registry was listed with www. clinicaltrials.gov and on most of the participating institution's clinical research web pages. All potentially eligible patients were screened by a study coordinator for potential enrollment. All patients who were eligible and who agreed to participate were asked to sign an institutional review board-approved consent form to participate in the study. The patient's treatment was not affected in any way for choosing not to participate in the study.

\section{Outcomes Assessment}

The primary end point of this study was the physical function domain from the general health-related quality of life (HRQOL) measure-the RAND Medical Outcomes Study SF-36. ${ }^{16}$ It was expected that all sites would have at least an $80 \%$ compliance rate for the completion of all outcomes questionnaires during the 1-year study period.

Patients completed one disease-specific outcome measure, the ODI, ${ }^{12}$ one general HRQOL measure, and the norm-based SF-36 ${ }^{16}$ preoperatively and $1,3,6$, and 12 months postoperatively. Return to work and complication 


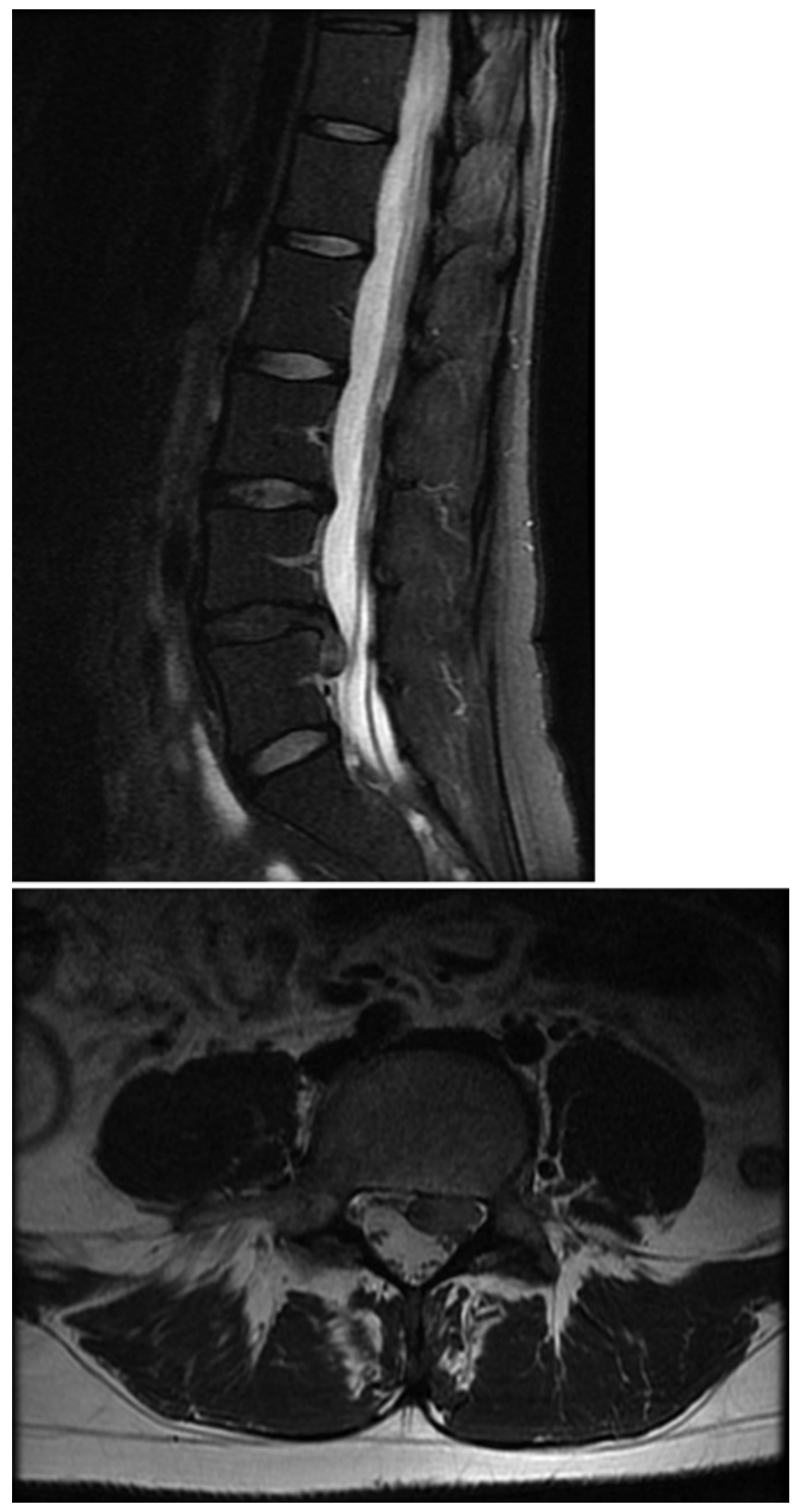

FIG. 1. Sagittal (upper) and axial (lower) MRI studies showing a symptomatic lumbar disc herniation.

assessments were completed by an independent study coordinator at each site. Complications included all major adverse events (death, myocardial infarction, pulmonary embolus, infection, CSF leakage, new neurological deficit [for example, foot drop], readmission, and repeat operation). Delayed complications (repeat operation, fusion complications, problems with instrumentation, deformity) were recorded at 1 year.

\section{Surgical Treatment}

All patients underwent surgery at the discretion of the surgeon and the patient. Lumbar discectomy was performed as described..$^{32}$ Decompression and instrumented pedicle screw lumbar spinal fixation and fusion, with or without interbody device placement, were performed in
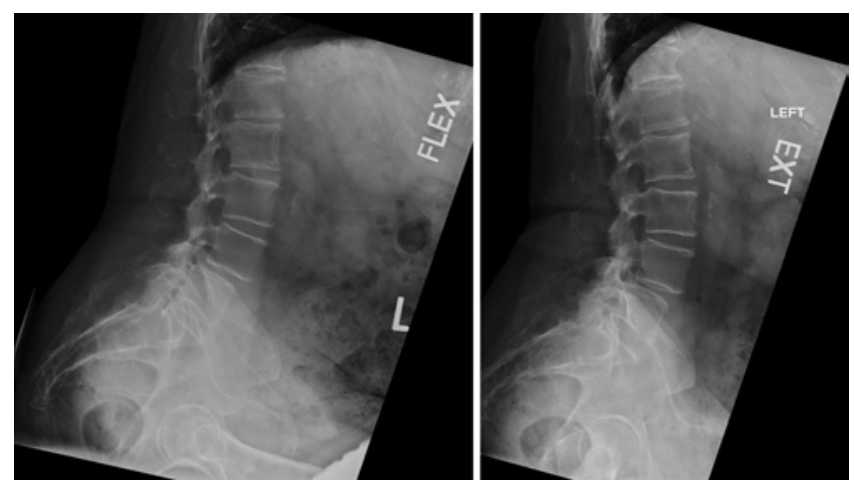

FIG. 2. Dynamic lumbar radiographs showing Grade I spondylolisthesis at L4-5.

all patients with isthmic or degenerative lumbar spondylolisthesis. ${ }^{13}$

\section{Study Sample Size Estimates}

Based on the published data for the patients with lumbar discectomy from the SPORT studies, ${ }^{38}$ we assumed a preoperative value of 30 for SF-36 physical function (standard deviation between 23 and 25), with treatment effect from 40 to 45 points. On 2 -sided t-tests, at a $5 \%$ significance level, we calculated that a sample size of 10 patients per site would be necessary to demonstrate the effectiveness of lumbar discectomy at $80 \%$ power, leading to the total sample size estimate for the lumbar discectomy cohort of 100 patients. The sample size was inflated to 125 patients to accommodate attrition during the follow-up.

Based on the published data for the spondylolisthesis patients from the SPORT study, ${ }^{37}$ we assumed a preoperative value of 40 for SF-36 physical function (standard deviation between 20 and 24), with a treatment effect of 30 points. On 2 -sided t-tests, at a $5 \%$ significance level, we calculated that a sample size of 25 patients would be necessary to demonstrate the effectiveness of the procedure for the spondylolisthesis cohort at $80 \%$ power. The sample size was inflated to 35 patients to accommodate attrition during the follow-up.

The total sample size estimate for statistical power was 160 patients [125 (lumbar discectomy) + 35 (lumbar spondylolisthesis)]. Based on the unpredictability of enrollment from individual sites, we increased the number of sites from 10 to 13 . Total enrollment was targeted at 200 unselected patients over a 1-year period. Sample size calculations were not specifically performed for the economic analysis or collection of cost data.

\section{Statistical Analysis}

A p value of $<0.05$ was considered statistically significant. Analyses were performed using Stata 12.1. To conduct a cost-effectiveness analysis, we first calculated utility gained at 1 year by converting SF-36 data to 6-dimension utility index (SF-6D) values by using ordinal and standard gamble health-state valuation models. ${ }^{3-5,23}$ The QALYs were determined by the change in utility between baseline and 1 year, multiplied by the duration of time in years ( 1 year in this study). ${ }^{15,31}$ Direct costs from a societal 
perspective for lumbar discectomy and single-level fusion were estimated using 2011 Medicare reimbursement values for current procedural terminology (CPT) codes and diagnosis-related group (DRG) codes (Table 1) (http:// www.cms.gov/apps/physician-fee-schedule/search/searchcriteria.aspx). ${ }^{6,76}$ Indirect costs were estimated using the human capital method; that is, the amount of missed work multiplied by the US national wage index from 2011 (http:// Www.ssa.gov/oact/cola/AWI.html). ${ }^{17}$ The cost of complications from lumbar discectomy and lumbar fusion was included if the complication resulted in a reoperation. In this instance, the direct cost of the complication was estimated from Medicare reimbursement values as described above. Direct costs did not include out-of-pocket or outpatient expenses, or costs derived from radiology, medicines, or physical devices associated with lumbar spinal surgery, although these costs are often accrued in the nonsurgical group as well.

Only patients who had both QALY and cost data were used for the cost analysis. To deal with missing data, both the mean imputation and last observation carried forward were used. Specifically, for patients missing return to work data, the average number of missed work days for each cohort (lumbar discectomy and lumbar fusion) were imputed and used to estimate indirect costs. For patients missing 1-year QALY data, the last observation carried forward was used for patients who had 6-month QALY data. Patients who did not have 6-month or 1-year QALY data were not included in the cost analysis. The final cost analysis included 172 patients; 126 lumbar discectomy and 46 lumbar fusion patients.

Total societal costs were estimated as direct costs plus indirect costs plus complication costs. The acceptable cost per additional QALY is a societal determination and serves as a foundation for cost-effectiveness analyses. Confidence intervals for the cost per QALY estimate were calculated using the nonparametric bootstrap method (http://www.stata.com/features/overview/bootstrapsampling-and-estimation/). The most recent literature cites $\$ 100,000 /$ QALY gained as the threshold for a costeffective intervention. ${ }^{2,20}$

\section{Results}

\section{Patient Population}

A total of 211 patients were screened and 198 were enrolled from 13 academic and community sites (mean 15 patients/site) over 1 year. The mean age was 46 years and median body mass index $27.3 \mathrm{~kg} / \mathrm{m}^{2}$ (49\% female, $2 \%$ with diabetes, and $21 \%$ smokers) for lumbar discectomy $(\mathrm{n}=148)$; and the mean age was 58.1 years and median body mass index $30 \mathrm{~kg} / \mathrm{m}^{2}$ (60\% female, $8 \%$ with diabetes, and $10 \%$ smokers) for lumbar spondylolisthesis ( $\mathrm{n}=$ 50) (Table 2).

\section{Compliance and Database Auditing}

Overall, there was $88.3 \%$ compliance (site range $25 \%-$ $97.3 \%$ ) with patient-reported outcomes data collection. The average period of enrollment at each site was 7.5 months. Target enrollment was capped at a maximum of 25 patients per site. Baseline evaluations were completed in $100 \%$ of patients. Outcomes assessment compliance (follow-up) was $87.4 \%, 86.9 \%$, and $83.3 \%$ at 3, 6, and 12 months, respectively. At 1 year, there was $83.3 \%$ compliance in completing an independent complications assessment.

\section{Outcome Assessments}

At 30 days, lumbar discectomy and single-level fusion procedures were associated with significant improvements in SF-36 scores ( $p=0.0002)$, which persisted over the 1-year follow-up. The SF-36 scores were converted to SF-6D scores to calculate QALYs gained. ${ }^{3}$ Lumbar discectomy was associated with a gain of 0.225 QALYs, and lumbar spinal fusion for Grade I spondylolisthesis was associated with a gain of 0.195 QALYs over the 1-year study period (Fig. 3).

\section{Postoperative Complications}

At 30 days, 12 complications (6.1\% of study population) were identified. Complications in the discectomy cohort included 4 wound infections, 2 new postoperative neurological deficits, and 4 reoperations at the surgically treated level. Complications in the spondylolisthesis cohort included 1 symptomatic CSF leak requiring hospitalization within 30 days and 1 aortic occlusion with nonfatal cardiac arrest. By 1-year follow-up, a total of 10 patients with disc herniation $(6.8 \%)$ and 1 with spondylolisthesis $(2 \%)$ required reoperations at the index level. One patient $(2 \%)$ in the spondylolisthesis cohort had a complication resulting from the instrumentation.

\section{Return to Work}

A total of 105 patients with disc herniation (70.9\%) and 24 with spondylolisthesis $(48 \%)$ were working preoperatively. By 1-year follow-up, more than $80 \%$ of the patients in each cohort who were working preoperatively had returned to work. The average time of missed work was 67 days $( \pm 86$ days $[\mathrm{SD}])$ for lumbar discectomy patients and 156 days ( \pm 130 days [SD]) for lumbar fusion patients. The economic cost associated with missed work following lumbar discectomy and for lumbar fusion is shown in Fig. 4.

TABLE 1: Medicare reimbursement rates in $\mathbf{2 0 1 1}$ for lumbar discectomy and lumbar fusion

\begin{tabular}{ccccc}
\hline Op & CPT Code $(s)$ & 2011 Medicare Reimbursement & DRG Code $^{*}$ & 2011 Medicare Reimbursement \\
\hline lumbar discectomy & 63030 & $\$ 961.53$ & 491 & $\$ 5536.22$ \\
lumbar fusion & 22630 & $\$ 1535.73$ & 460 & $\$ 21,617.69$ \\
& 22842 & $\$ 779.76$ & & \\
& 63047 & $\$ 1095.06$ & & \\
\hline
\end{tabular}

* The DRG codes were selected assuming patients did not have major comorbidities. 
Cost-effectiveness of lumbar discectomy and fusion

TABLE 2: Summary statistics of the NeuroPoint-SD registry*

\begin{tabular}{lcc}
\hline \multicolumn{1}{c}{ Variable } & Lumbar Discectomy & Lumbar Fusion \\
\hline no. of patients & 148 & 50 \\
age in yrs & $46.0 \pm 12.6(18-77)$ & $58.1 \pm 13.4(25-78)$ \\
sex (\% female) & $48.6 \%$ & $60.4 \%$ \\
baseline ODI & $46.73 \pm 18.7(0-96)$ & $45.31 \pm 16.08(22-84)$ \\
baseline SF-36 & $38.14 \pm 23.90(0-95)$ & $31.80 \pm 23.94(0-85)$ \\
baseline SF-6D & $0.517 \pm 0.122(0.179-0.814)$ & $0.516 \pm 0.121(0.279-0.748)$ \\
1-mo SF-6D & $0.634 \pm 0.149(0.301-0.917)$ & $0.613 \pm 0.133(0.363-0.914)$ \\
3-mo SF-6D & $0.723 \pm 0.141(0.210-0.973)$ & $0.674 \pm 0.134(0.282-0.914)$ \\
6-mo SF-6D & $0.744 \pm 0.147(0.282-0.973)$ & $0.710 \pm 0.135(0.251-0.941)$ \\
1-yr SF-6D & $0.774 \pm 0.143(0.385-0.973)$ & $0.727 \pm 0.149(0.282-0.973)$ \\
\hline
\end{tabular}

* Values are presented as the mean \pm SD (range), unless otherwise noted.

\section{Economic Analysis}

Total costs for lumbar discectomy are $\$ 14,980$ (Table $3)$. The direct cost for reoperation for lumbar discectomy was estimated as \$6498 from 2011 Medicare reimbursement values. The average cost of complications for lumbar discectomy was $\$ 464$, including all reoperations. The calculated cost per QALY for lumbar discectomy is $\$ 66,578$ (95\% CI \$55,858-\$77,439). Total costs for single-level lumbar fusion are $\$ 43,852$ (Fig. 5). The direct cost of reoperation for lumbar fusion was estimated as $\$ 25,028$. The average cost of complications for lumbar fusion was $\$ 544$, including all reoperations. The cost per QALY for single-level lumbar spinal fusion is $\$ 224,420$ (95\% CI \$170,686-\$278,154) at the 1-year time point.

\section{Discussion}

NeuroPoint-SD represents the first multicenter prospective registry to demonstrate clinical effectiveness for lumbar discectomy and single-level lumbar fusion at 1 year. Fusion for Grade I spondylolisthesis is not costeffective at 1 year, but the gain in QALYs associated with lumbar fusion suggests that it will become cost-effective over a 2-year period. Unfortunately, we will not be able to verify this with our own data due to the restricted time frame of 1 year in our pilot project database. It is relevant to note that in the SPORT study, the observed improvement following a single-level lumbar fusion was durable

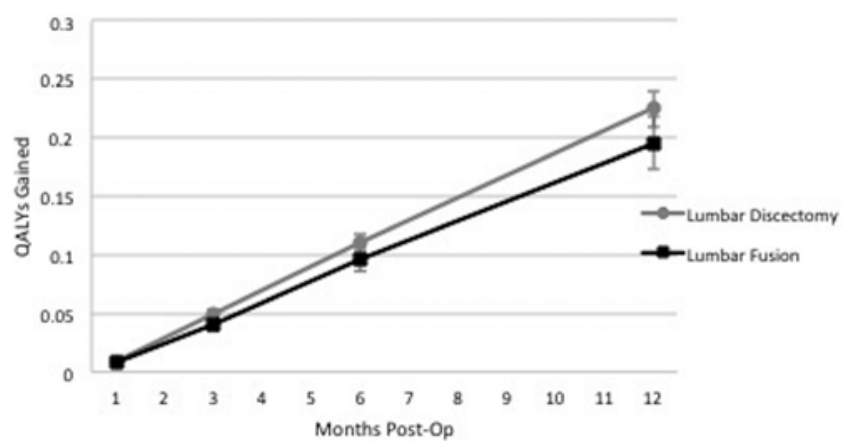

FIG. 3. Graph showing QALYs gained as a result of lumbar discectomy and lumbar fusion. for more than 2 years. ${ }^{33,37}$ If the observed improvements in the NeuroPoint-SD cohort are durable for at least 2-4 years as observed in the SPORT study, then the cost per QALY will drop significantly. ${ }^{35}$

The NeuroPoint-SD registry has created infrastructure to prospectively measure outcomes and costs of all common spinal procedures. The difficulties faced in previous trials related to the heterogeneity of patients with spine disorders and to the surgeries performed will be mitigated by the larger sample size, real practice conditions, and prolonged follow-up. In the upcoming era of quality improvement and cost containment, spine registries will need to be capable of monitoring not only the complications from procedures but their costs as well. ${ }^{1}$

It is important to highlight that although some of the existing data on QALY comes from RCTs, the RCTs may not represent the real world, and the cost of an RCT may hinder the sustainability of such studies. The authors in this study have evaluated real-world populations from a diverse group of institutions engaged in day-to-day surgical care. By the nature of the database, not only is it sustainable, but it also could provide a realistic means to accurately track QALY over time rather than in unique situations.

\section{Cost per QALY Comparisons}

The results of this analysis are consistent with the existing literature for lumbar spinal surgery. Tosteson et al. reported that surgery, including fusion, for degenerative

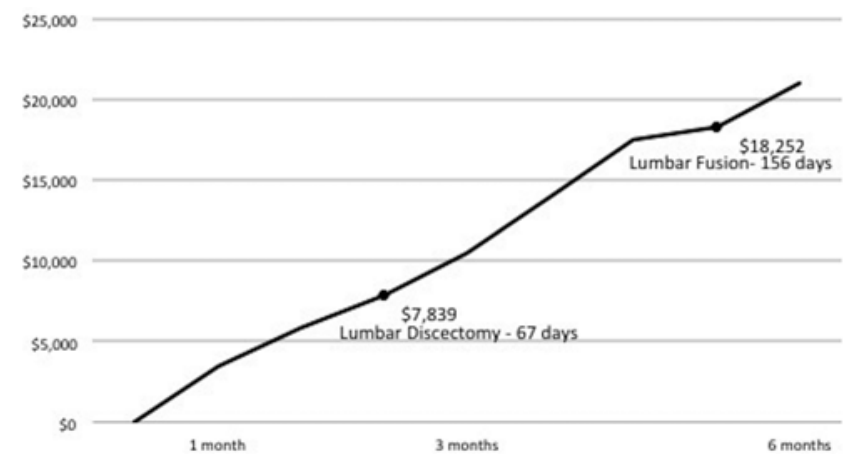

Fig. 4. Graph showing cost in dollars (\$) of missed work days for lumbar discectomy and lumbar fusion. 
TABLE 3: Costs of lumbar discectomy and lumbar fusion*

\begin{tabular}{ccccc}
\hline Op & Direct Cost & Indirect Cost & Complication Cost & Total Cost \\
\hline lumbar discectomy & $\$ 6498$ & $\$ 8018$ & $\$ 464$ & $\$ 14,980$ \\
lumbar fusion & $\$ 25,028$ & $\$ 18,280$ & $\$ 544$ & $\$ 43,852$ \\
\hline
\end{tabular}

${ }^{*}$ All costs represent the average.

spondylolisthesis was associated with a gain in QALYs of 0.23 at a cost of $\$ 115,600$ over a 2 -year period. ${ }^{33}$ Similarly, lumbar discectomy was associated with a gain of 0.21 QALYs at a cost of $\$ 34,355$ over a 2 -year period. ${ }^{34}$ The durable gains in outcome at 1 year in this study are likely to persist based on prior literature, causing the value of operative intervention for lumbar discectomy and lumbar fusion to improve over time. ${ }^{35}$ At 4-year follow-up, the cost per QALY for surgery to treat degenerative spondylolisthesis decreased from $\$ 115,600$ to $\$ 64,300 .{ }^{35}$

There is extensive orthopedic literature on the costeffectiveness of total joint replacement that can be referenced for comparative purposes. A recent review reported that total hip arthroplasty is associated with a cost per QALY gained of \$10,402 in 2011 \$US for the duration of a patient's life, and total knee arthroplasty ranges from $\$ 13,000 / \mathrm{QALY}$ over a 5-year time period to $\$ 22,000$ / QALY for the duration of a patient's life. ${ }^{10}$ The addition of computer navigation to improve limb and arthroplasty component alignment for total knee arthroplasty increases the cost per QALY to \$54,234 over a 15 -year period, but improves precision of the implant by $14 \% .{ }^{11}$ In addition, patients at higher risk for surgery due to comorbidities who underwent total knee arthroplasty were associated with a significantly higher cost per QALY of $\$ 135,700 .{ }^{21}$ Although these studies report cost per QALY values for total joint arthroplasty that are more cost-effective than those for lumbar discectomy and lumbar fusion reported in this study, the time period of outcome measurement is also significantly longer. Polly et al. directly compared the cost/benefit ratio of lumbar fusion to total joint arthroplasty and coronary artery bypass surgery by using data from several randomized clinical trials. ${ }^{26}$ Lumbar fusion had a lower cost per outcome (SF-36) improvement than coronary artery bypass surgery, equivalent to total knee arthroplasty, and slightly higher cost per outcome improvement compared with total knee arthroplasty at 1 and 2 years following surgery.

Several studies have compared the outcomes following joint arthroplasty to surgery for lumbar spine disorders. Rampersaud et al. performed a direct comparison of the outcomes following surgery for focal lumbar spinal stenosis, total hip arthroplasty, and total knee arthroplasty at 1-year and 2-year follow-up. ${ }^{27} \mathrm{~A}$ subgroup analysis of patients who received lumbar fusion (with or without spondylolisthesis) showed that they attained improvement in HRQOL scores equal to total hip arthroplasty. Similar results were demonstrated by a follow-up multicenter prospective trial conducted by the same group. ${ }^{28}$ Mokhtar et al. reported equivalent improvement by SF-12 at 2 years for patients who underwent surgery for lumbar spondylolisthesis compared with total hip arthroplasty, and superior improvements compared with total knee arthroplasty. ${ }^{24}$ The gain in QALYs was reported to be between 0.3 and 0.4 for total hip arthroplasty and between 0.15 and 0.3 for total knee arthroplasty. ${ }^{19,21}$ The gain in QALYs following surgical intervention is highly variable, depending on patient-specific factors such as the type of arthritis prompting arthroplasty. For patients with inflammatory arthropathies such as rheumatoid arthritis, the gain in QALY at 1 year after total joint arthroplasty is reported to be very small: 0.10 using EQ-5D and 0.03 with SF-6D. ${ }^{25}$

These orthopedic large-joint replacement studies serve as important comparisons for this analysis. The outcomes and costs following surgery are highly dependent on patient selection. Although the NeuroPoint-SD registry has some limited exclusion criteria, the majority of patients with lumbar spine disorders, including those with rheumatoid arthritis, are included and combined with patients with simple degenerative arthritis. This pilot eco-

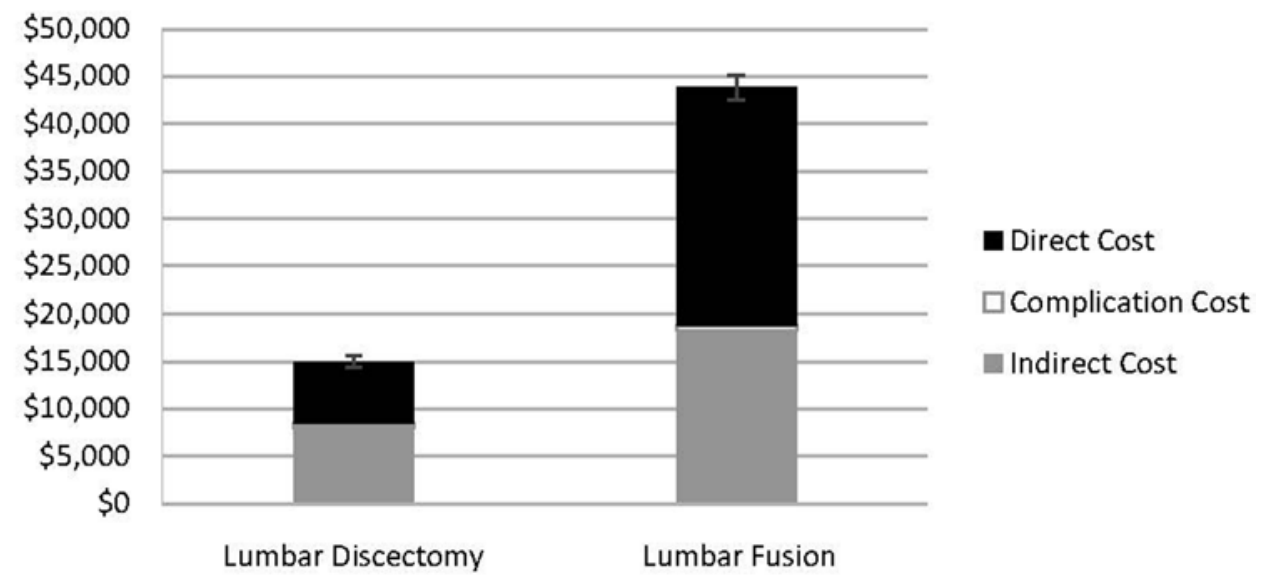

Fig. 5. Bar graph showing direct, indirect, and complication costs of lumbar discectomy and lumbar fusion. 
nomic analysis has demonstrated that lumbar discectomy is cost-effective, despite the increased heterogeneity of the patient population captured in the actual practice conditions of this registry. With longer follow-up and larger sample size, the true value of surgeries for lumbar spine disorders may be determined.

\section{Limitations of the Study}

There are several limitations with this study. In its initial phase, NeuroPoint-SD did not collect cost data in a prospective fashion. Therefore, all cost data reported in this study are estimates, based on 2011 Medicare reimbursement values and with CPT and DRG code assumptions. The cost data do not include out-of-pocket, outpatient, medication, device, radiological, or anesthesia expenses. The true societal cost of these procedures is likely to be higher, particularly when these additional variables are included.

The gain in QALY reported in this paper may be inaccurate because we assume that all changes in utility are the result of surgery. In reality, many other factors such as patient bias toward surgery, participation in conservative therapies, and the passage of time may contribute to changes in QALY. An incremental cost-effectiveness ratio could not be calculated for this analysis because outcomes and costs of nonoperative treatments for lumbar discectomy and lumbar fusion were not recorded. Calculation of the incremental cost-effectiveness ratio is currently the gold standard of cost-effectiveness analysis as it pertains to surgical intervention.

This cost analysis is also limited by the small sample size. Indirect costs were highly variable (Table 3 ) in this study population and represented a substantial percentage of the total costs. There were several outlier patients who may have skewed the results of indirect costs, such as a patient who underwent lumbar discectomy and missed more than 400 days of work. It is unclear if these patients had some secondary incentive to miss work such as receiving worker's compensation or disability.

\section{Conclusions}

The NeuroPoint-SD registry has demonstrated clinical effectiveness of lumbar discectomy and single-level lumbar fusion for Grade I lumbar spondylolisthesis at 1 year. Lumbar discectomy is cost-effective at 1 year, assuming a $\$ 100,000 /$ QALY gained societal willingness-to-pay threshold. In the short-term follow-up, lumbar fusion is not cost-effective; however, reported long-term follow-up for patients with lumbar spinal fusion has demonstrated the cost-effectiveness of many of these procedures. Spine registries represent a unique opportunity. This lumbar spine registry has set the stage for a much larger initiative to collect outcomes and cost data on heterogeneous patient populations involving multiple institutions.

\section{Acknowledgment}

The work was coordinated by the NPA.

\section{Disclosure}

Funding was provided by the AANS/CNS Joint Section on
Disorders of the Spine and Peripheral Nerves, the AANS, and the Jean and David Wallace Foundation (GH382). Dr. Heary receives royalties from DePuy Synthes Spine, Zimmer Spine, and Thieme Medical Publishers. Dr. Malhotra is a consultant for Stryker Spine. Dr. Mummaneni receives royalties and honoraria from DePuy Spine, honoraria from Globus, royalties from Thieme Medical Publishers, and royalties from Quality Medical Publishing. He owns stock in Spinicity. Dr. Smith is a consultant for Biomet, Globus, Medtronic, and DePuy, and he receives support from ISSGF/DePuy for a non-study-related clinical or research effort that he oversees. Dr. Ghogawala received clinical or research support for this study from the Wallace Foundation. Dr. Shaffrey is a consultant for Biomet, Globus, Medtronic, NuVasive, and Stryker. He has patents with and receives royalties from Biomet and Medtronic.

Author contributions to the study and manuscript preparation include the following. Conception and design: Ghogawala, Mummaneni, Resnick, Shaffrey. Acquisition of data: Ghogawala, Mummaneni, Whitmore, Shaffrey, Asher, Heary, Cheng, Hurlbert, Douglas, Smith, Malhotra, Dante, Magge, Kaiser, Resnick. Analysis and interpretation of data: Ghogawala, Whitmore, Curran, Wadhwa. Drafting the article: Ghogawala, Mummaneni, Curran, Ziewacz, Wadhwa, Whitmore. Critically revising the article: Ghogawala, Mummaneni. Reviewed submitted version of manuscript: Ghogawala, Mummaneni, Whitmore, Curran, Ziewacz, Wadhwa, Malhotra, Shaffrey, Asher, Heary, Cheng, Hurlbert, Kaiser, Resnick. Statistical analysis: Whitmore, Curran. Administrative/technical/ material support: Ghogawala, Curran.

\section{References}

1. Amin BY, Tu TH, Schairer WW, Na L, Takemoto S, Berven S, et al: Pitfalls of calculating hospital readmission rates based on nonvalidated administrative data sets. Clinical article. J Neurosurg Spine 18:134-138, 2013

2. Braithwaite RS, Meltzer DO, King JT Jr, Leslie D, Roberts MS: What does the value of modern medicine say about the $\$ 50,000$ per quality-adjusted life-year decision rule? Med Care 46:349-356, 2008

3. Brazier J, Roberts J, Deverill M: The estimation of a preference-based measure of health from the SF-36. J Health Econ 21:271-292, 2002

4. Brazier J, Usherwood T, Harper R, Thomas K: Deriving a preference-based single index from the UK SF-36 Health Survey. J Clin Epidemiol 51:1115-1128, 1998

5. Brazier JE, Roberts J: The estimation of a preference-based measure of health from the SF-12. Med Care 42:851-859, 2004

6. Centers for Medicare and Medicaid Services: FY 2011 Final Rule Data Files. (http://www.cms.gov/Medicare/MedicareFee-for-Service-Payment/AcuteInpatientPPS/FY-2011-IPPSFinal-Rule-Home-Page-Items/CMS1237932.html?DLPage= 1\&DLSort=0\&DLSortDir=ascending] [Accessed April 29, 2014]

7. Chulis GS: Assessing Medicare's prospective payment system for hospitals. Med Care Rev 48:167-206, 1991

8. Dagenais S, Caro J, Haldeman S: A systematic review of low back pain cost of illness studies in the United States and internationally. Spine J 8:8-20, 2008

9. Dagenais S, Roffey DM, Wai EK, Haldeman S, Caro J: Can cost utility evaluations inform decision making about interventions for low back pain? Spine J 9:944-957, 2009

10. Daigle ME, Weinstein AM, Katz JN, Losina E: The cost-effectiveness of total joint arthroplasty: a systematic review of published literature. Best Pract Res Clin Rheumatol 26:649-658, 2012

11. Dong H, Buxton M: Early assessment of the likely cost-effectiveness of a new technology: a Markov model with probabilistic sensitivity analysis of computer-assisted total knee replacement. Int J Technol Assess Health Care 22:191-202, 2006

12. Fairbank JC, Couper J, Davies JB, O'Brien JP: The Oswes- 
try low back pain disability questionnaire. Physiotherapy 66:271-273, 1980

13. Ghogawala Z, Benzel EC, Amin-Hanjani S, Barker FG II, Harrington JF, Magge SN, et al: Prospective outcomes evaluation after decompression with or without instrumented fusion for lumbar stenosis and degenerative Grade I spondylolisthesis. J Neurosurg Spine 1:267-272, 2004

14. Ghogawala Z, Shaffrey CI, Asher AL, Heary RF, Logvinenko T, Malhotra NR, et al: The efficacy of lumbar discectomy and single-level fusion for spondylolisthesis: results from the NeuroPoint-SD registry. Clinical article. J Neurosurg Spine 19: 555-563, 2013

15. Gold MR, Franks P, McCoy KI, Fryback DG: Toward consistency in cost-utility analyses: using national measures to create condition-specific values. Med Care 36:778-792, 1998

16. Hays RD, Sherbourne CD, Mazel RM: The RAND 36-Item Health Survey 1.0. Health Econ 2:217-227, 1993

17. Hodgson TA, Meiners MR: Cost-of-illness methodology: a guide to current practices and procedures. Milbank Mem Fund Q Health Soc 60:429-462, 1982

18. Institute of Medicine: 100 Initial Priority Topics for Comparative Effectiveness Research. (http://www.iom.edu/ /me dia/Files/Report\%20Files/2009/ComparativeEffectivenessRe searchPriorities/Stand\%20Alone\%20List\%20of\%20100\%20 CER\%20Priorities\%20-\%20for\%20web.ashx) [Accessed April 29, 2014]

19. Jenkins PJ, Clement ND, Hamilton DF, Gaston P, Patton JT, Howie CR: Predicting the cost-effectiveness of total hip and knee replacement: a health economic analysis. Bone Joint J 95-B:115-121, 2013

20. Kepler CK, Wilkinson SM, Radcliff KE, Vaccaro AR, Anderson DG, Hilibrand AS, et al: Cost-utility analysis in spine care: a systematic review. Spine J 12:676-690, 2012

21. Losina E, Walensky RP, Kessler CL, Emrani PS, Reichmann WM, Wright EA, et al: Cost-effectiveness of total knee arthroplasty in the United States: patient risk and hospital volume. Arch Intern Med 169:1113-1122, 2009

22. Martin BI, Deyo RA, Mirza SK, Turner JA, Comstock BA, Hollingworth W, et al: Expenditures and health status among adults with back and neck problems. JAMA 299:656-664, 2008

23. McCabe C, Brazier J, Gilks P, Tsuchiya A, Roberts J, O’Hagan A, et al: Using rank data to estimate health state utility models. J Health Econ 25:418-431, 2006

24. Mokhtar SA, McCombe PF, Williamson OD, Morgan MK, White GJ, Sears WR: Health-related quality of life: a comparison of outcomes after lumbar fusion for degenerative spondylolisthesis with large joint replacement surgery and population norms. Spine J 10:306-312, 2010

25. Osnes-Ringen H, Kvamme MK, Kristiansen IS, Thingstad M, Henriksen JE, Kvien TK, et al: Cost-effectiveness analyses of elective orthopaedic surgical procedures in patients with inflammatory arthropathies. Scand J Rheumatol 40:108-115, 2011

26. Polly DW Jr, Glassman SD, Schwender JD, Shaffrey CI, Branch C, Burkus JK, et al: SF-36 PCS benefit-cost ratio of lumbar fusion comparison to other surgical interventions: a thought experiment. Spine (Phila Pa 1976) 32 (11 Suppl):S20-S26, 2007

27. Rampersaud YR, Ravi B, Lewis SJ, Stas V, Barron R, Davey R, et al: Assessment of health-related quality of life after surgical treatment of focal symptomatic spinal stenosis compared with osteoarthritis of the hip or knee. Spine J 8:296-304, 2008

28. Rampersaud YR, Wai EK, Fisher CG, Yee AJ, Dvorak MF, Finkelstein JA, et al: Postoperative improvement in healthrelated quality of life: a national comparison of surgical treatment for focal (one- to two-level) lumbar spinal stenosis com- pared with total joint arthroplasty for osteoarthritis. Spine J 11:1033-1041, 2011

29. Resnick DK, Choudhri TF, Dailey AT, Groff MW, Khoo L, Matz PG, et al: Guidelines for the performance of fusion procedures for degenerative disease of the lumbar spine. Part 9: fusion in patients with stenosis and spondylolisthesis. J Neurosurg Spine 2:679-685, 2005

30. Resnick DK, Choudhri TF, Dailey AT, Groff MW, Khoo L, Matz PG, et al: Guidelines for the performance of fusion procedures for degenerative disease of the lumbar spine. Part 10: fusion following decompression in patients with stenosis without spondylolisthesis. J Neurosurg Spine 2:686-691, 2005

31. Russell LB, Gold MR, Siegel JE, Daniels N, Weinstein MC: The role of cost-effectiveness analysis in health and medicine. JAMA 276:1172-1177, 1996

32. Spengler DM: Lumbar discectomy. Results with limited disc excision and selective foraminotomy. Spine (Phila Pa 1976) 7:604-607, 1982

33. Tosteson AN, Lurie JD, Tosteson TD, Skinner JS, Herkowitz $\mathrm{H}$, Albert T, et al: Surgical treatment of spinal stenosis with and without degenerative spondylolisthesis: cost-effectiveness after 2 years. Ann Intern Med 149:845-853, 2008

34. Tosteson AN, Skinner JS, Tosteson TD, Lurie JD, Andersson GB, Berven S, et al: The cost effectiveness of surgical versus nonoperative treatment for lumbar disc herniation over two years: evidence from the Spine Patient Outcomes Research Trial (SPORT). Spine (Phila Pa 1976) 33:2108-2115, 2008

35. Tosteson AN, Tosteson TD, Lurie JD, Abdu W, Herkowitz H, Andersson G, et al: Comparative effectiveness evidence from the spine patient outcomes research trial: surgical versus nonoperative care for spinal stenosis, degenerative spondylolisthesis, and intervertebral disc herniation. Spine (Phila Pa 1976) 36:2061-2068, 2011

36. Tumeh JW, Moore SG, Shapiro R, Flowers CR: Practical approach for using Medicare data to estimate costs for cost-effectiveness analysis. Expert Rev Pharmacoecon Outcomes Res 5:153-162, 2005

37. Weinstein JN, Lurie JD, Tosteson TD, Hanscom B, Tosteson AN, Blood EA, et al: Surgical versus nonsurgical treatment for lumbar degenerative spondylolisthesis. N Engl J Med 356: 2257-2270, 2007

38. Weinstein JN, Lurie JD, Tosteson TD, Skinner JS, Hanscom B, Tosteson AN, et al: Surgical vs nonoperative treatment for lumbar disk herniation: the Spine Patient Outcomes Research Trial (SPORT) observational cohort. JAMA 296:2451-2459, 2006

39. Weinstein JN, Tosteson TD, Lurie JD, Tosteson AN, Blood E, Hanscom B, et al: Surgical versus nonsurgical therapy for lumbar spinal stenosis. N Engl J Med 358:794-810, 2008

40. Weinstein JN, Tosteson TD, Lurie JD, Tosteson AN, Hanscom B, Skinner JS, et al: Surgical vs nonoperative treatment for lumbar disk herniation: the Spine Patient Outcomes Research Trial (SPORT): a randomized trial. JAMA 296:2441-2450, 2006

Manuscript submitted February 10, 2014.

Accepted March 25, 2014.

An abstract of this study received 2 nd place in the socioeconomic category at the 2014 AANS Annual Meeting.

Please include this information when citing this paper: DOI: 10.3171/2014.3.FOCUS1450.

Address correspondence to: Zoher Ghogawala, M.D., Lahey Comparative Effectiveness Research Institute, Lahey Hospital and Medical Center, 41 Mall Rd., Burlington, MA 01805. email: zoher. ghogawala@lahey.org. 